\title{
Abnormal Fibrinogens: Almost a Century from the First Case Reported. Is it Time for Guidelines?
}

\section{Rita Marchi Cappelletti*}

Center for Experimental Medicine, Developmental Biology Laboratory of Hemostasis, Venezuelan Institute for Scientific Research, Caracas, Bolivarian Republic of Venezuela

"Corresponding author: Rita Marchi Cappelletti, Center for Experimental Medicine, Developmental Biology Laboratory of Hemostasis, Venezuelan Institute for Scientific Research, Caracas, Bolivarian Republic of Venezuela, Tel: (+58)212-5041526; Fax: (+58)212-5041086; E-mail: rmarchi@ivic.gob.ve

Received date: May 13, 2016, Accepted date: May 17, 2016, Publication date: May 20, 2016

Copyright: ( 2016 Cappelletti RM. This is an open-access article distributed under the terms of the Creative Commons Attribution License, which permits unrestricted use, distribution, and reproduction in any medium, provided the original author and source are credited.

Citation: Cappelletti RM (2016) Abnormal Fibrinogens: Almost a Century from the First Case Reported. Is it Time for Guidelines?. J Blood Disord Transfus 7: 354. doi: 10.4172/2155-9864.1000354

Fibrinogen is the building block of blood clots. Congenital abnormal fibrinogen is a rare blood disorder with a frequency of $1: 10^{6}$. It is encoded by three genes FGA, FGB and FGG. Approximately 50\% are clinically silent, while $25 \%$ can be bleeders (generally mild) or thrombotic. Fibrinogen disorders can also be acquired. Some pathological states could cause posttranslational fibrinogen modifications, for example oxidation, nitration, homocysteinylation and glycation [1]. Furthermore, viral infections as dengue, valproic acid intake, can cause a transitory dys- or hypo- fibrinogenemia. Congenital fibrinogen disorders are classified as quantitative (type I) and qualitative (type II). In type I, the fibrinogen can be completely absent or very low (afibrinogenemia, $<0.1 \mathrm{~g} / \mathrm{L}$ ) or between 0.1 and $<1.5$ $\mathrm{g} / \mathrm{L}$ (hypofibrinogenemia) [2]. The qualitative fibrinogen disorders are known as dysfibrinogenemia, the abnormal protein is expressed impairing specific fibrin (ogen) functions. There is also a combination of dys- with diminished antigenic levels (hypodysfibrinogenemia). Dysfibrinogenemia inheritance is autosomal dominant while that of aor hypo- fibrinogenemia is autosomal recessive [2]. The study of dysfibrinogenemias has helped to elucidate the fibrinogen structurefunction relationship.

The clinical outcome of afibrinogenemia is bleeding from mild to severe, and paradoxical thrombosis can occur, due to the lack of the antithrombin I fibrin activity. Hypofibrinogenemic patients are often asymptomatic [3]. However, patients with dysfibrinogenemia have an unpredictable clinical phenotype; affected family members can have different symptomatology. Probably this inconsistency can be clarify by performing more detailed studies, which include the level of expression of the mutated molecules, the presence of the Aa Ala312thr and $\mathrm{B} \beta$ Arg448Lys fibrinogen polymorphisms, the proportion of the fibrinogen $\gamma$ factor XIII polymorphisms (Val34Leu), among other polymorphisms or mutations of other coagulation/fibrinolytic factors that are influencing the patient phenotype. Until now, there are not guidelines to study abnormal fibrinogens. Most of the studies performed depend on the mutation found, which is expected, however a minimum of common structural/function studies could be advisable in the future.

\section{References}

1. Henschen-Edman AH (2001) Fibrinogen non-inherited heterogeneity and its relationship to function in health and disease. Ann N Y Acad Sci 936: 580-593.

2. Asselta R, Duga S, Tenchini ML (2006) The molecular basis of quantitative fibrinogen disorder. J Thromb Haemost 4: 2115-2229.

3. Neerman-Arbez M, de Moerloose P, Casini A (2016) Laboratory and genetic investigation of mutations accounting for congenital fibrinogen disorders. Semin Thromb Hemost. 